\title{
Abgekürzt zitiertes Schrifttum
}

\author{
zum Mitbestimmungsrecht \\ Beuthien \\ Genossenschaftsgesetz, 13. Aufl 2000 \\ Boldt \\ Mitbestimmungsgesetz Eisen und Kohle, Kommentar, \\ 1952 (zit: Boldt MontanMitbestG) \\ Boldt \\ Mitbestimmungsergänzungsgesetz, Kommentar, 1957 \\ (zit: Boldt MitbestEG) \\ Däubler \\ Das Grundrecht auf Mitbestimmung, 3. Aufl 1975 \\ Fitting/Wlotzke/ \\ Wißmann \\ Mitbestimmungsgesetz, 2. Aufl 1978 \\ Gemeinschafts- \\ zum Mitbestimmungsgesetz, hrsg von Fabricius, \\ kommentar \\ bearbeitet von Fabricius, Matthes, Naendrup, Rumpff, \\ Schneider, Westerath, $1976 \mathrm{ff}$ \\ (zit: GemKomm.MitbestG/Bearb) \\ Gewerkschafts- \\ kommentar \\ zum Mitbestimmungsgesetz 1976, bearbeitet \\ von Benze, Föhr, Kehrmann, Kieser, Lichtenstein, \\ Schwegler, Unterhinninghofen, 1977 \\ (zit: GewKomm.MitbestG/Bearb) \\ Fuchs/Köstler \\ Handbuch zur Aufsichtsratswahl, 2. Aufl 2002 \\ Haberland/Seiler \\ Mitbestimmungsgesetz, 2. Aufl 1977 \\ Hanau/Ulmer \\ Mitbestimmungsgesetz, 1981 \\ Hoffmann/Lehmann/ Mitbestimmungsgesetz, 1978 \\ Weinmann \\ Köstler/Kittner/ \\ Aufsichtsratspraxis, 6. Aufl 2000 \\ Zachert \\ Kötter \\ Mitbestimmungsrecht, Kommentar, 1952 \\ Kötter \\ Mitbestimmungsergänzungsgesetz, Kommentar, 1958 \\ Meilicke/Meilicke \\ Mitbestimmungsgesetz 1976, 2. Aufl 1976 \\ Säcker \\ Die Wahlordnungen zum Mitbestimmungsgesetz, \\ 1978 \\ Wienke \\ Die Wahlordnungen zum Mitbestimmungsgesetz, \\ 4. Aufl 1992
}




\begin{tabular}{|c|c|}
\hline \multicolumn{2}{|c|}{ Abgekürzt zitiertes Schrifttum } \\
\hline \multicolumn{2}{|c|}{ zum Gesellschaftsrecht } \\
\hline Baumbach/Hueck & Aktiengesetz, 13. Aufl 1968 \\
\hline Baumbach/Hueck & $\begin{array}{l}\text { GmbH-Gesetz, 17. Aufl } 2000 \\
\text { (zit: Baumbach/Hueck/Bearb.) }\end{array}$ \\
\hline $\begin{array}{l}\text { Emmerich/Sonnen- } \\
\text { schein/Habersack }\end{array}$ & Konzernrecht, 7. Aufl 2001 \\
\hline Geßler/Hefermehl & $\begin{array}{l}\text { Aktiengesetz, } 1973 \mathrm{ff} \\
\text { (zit: Bearb in Geßler/Hefermehl AktG) }\end{array}$ \\
\hline Godin/Wilhelmi & Aktiengesetz, 4. Aufl 1971 \\
\hline Großkommentar & $\begin{array}{l}\text { zum Aktiengesetz, 3. Aufl } 1970 \text { ff; } 4 \text {. Aufl } 1992 \text { ff } \\
\text { (zit: GroßKomm.AktG/Bearb) }\end{array}$ \\
\hline Großkommentar & $\begin{array}{l}\text { zum HGB, 3. Aufl } 1967 \mathrm{ff}, 4 \text {. Aufl } 1983 \mathrm{ff} \\
\text { (zit: GroßKomm.HGB/Bearb) }\end{array}$ \\
\hline Hachenburg & $\begin{array}{l}\text { GmbH-Gesetz, 8. Aufl } 1990 \mathrm{ff} \\
\text { (zit: Hachenburg/Bearb) }\end{array}$ \\
\hline Kölner Kommentar & $\begin{array}{l}\text { zum Aktiengesetz, 2. Aufl } 1986 \text { ff } \\
\text { (zit: KölnKomm-AktG/Bearb) }\end{array}$ \\
\hline Hoffmann/Preu & Der Aufsichtsrat, 4. Aufl 1999 \\
\hline Hüffer & Aktiengesetz, 5. Aufl 2002 \\
\hline $\begin{array}{l}\text { Köstler/Kittner/ } \\
\text { Zachert }\end{array}$ & Aufsichtsratspraxis, 6. Aufl 2000 \\
\hline $\begin{array}{l}\text { Lang/Weidmüller/ } \\
\text { Metz/Schaffland }\end{array}$ & $\begin{array}{l}\text { Genossenschaftsgesetz, 33. Aufl } 1997 \\
\text { (zit: Lang/Weidmüller/Bearb) }\end{array}$ \\
\hline Lutter (Hrsg) & $\begin{array}{l}\text { Umwandlungsgesetz, 2. Aufl } 2000 \\
\text { (zit: Lutter/Bearb, UmwG) }\end{array}$ \\
\hline Lutter/Hommelhoff & GmbH-Gesetz, 15. Aufl 2000 \\
\hline Lutter/Krieger & Rechte und Pflichten des Aufsichtsrats 3. Aufl 1993 \\
\hline Müller & $\begin{array}{l}\text { Gesetz betreffend die Erwerbs- und Wirtschafts- } \\
\text { genossenschaften, } 2 \text {. Aufl } 1991 \mathrm{ff}\end{array}$ \\
\hline $\begin{array}{l}\text { Münchener } \\
\text { Handbuch des } \\
\text { Gesellschaftsrechts }\end{array}$ & $\begin{array}{l}\text { Bd } 4 \text { Aktiengesellschaft, 2. Aufl } 1999 \\
\text { (zit: MünchHdb-AG/Bearb) }\end{array}$ \\
\hline Raiser & Recht der Kapitalgesellschaften, 3. Aufl 2001 \\
\hline Roth/Altmeppen & GmbHG Kommentar, 3. Aufl 1997 \\
\hline Rowedder (Hrsg) & $\begin{array}{l}\text { GmbH-Gesetz, 3. Aufl } 1996 \\
\text { (zit: Rowedder/Bearb) }\end{array}$ \\
\hline K. Schmidt & Gesellschaftsrecht, 3. Aufl 1997 \\
\hline
\end{tabular}


Scholz

Wiedemann

zum Arbeitsrecht

Richardi

Fitting/Kaiser/

Heither/Engels

Gemeinschafts-

kommentar

Gnade/Kehrmann/ Schneider/Blanke

Löwisch

Münchener

Handbuch

des Arbeitsrechts

\section{Sonstiges}

Münchener

Kommentar

Staudinger
GmbH-Gesetz, 8. Aufl 1993/94; Bd 1, 9. Aufl 2000 (zit: Scholz/Bearb)

Gesellschaftsrecht Bd 1, 1980

Betriebsverfassungsgesetz, 8. Aufl 2002

Betriebsverfassungsgesetz, 20. Aufl 2000

zum Betriebsverfassungsgesetz, bearbeitet von Fabricius, Kraft, Wiese, Kreutz, 5. Aufl 1994-1998 (zit: GemKommBetrVG/Bearb)

Betriebsverfassungsgesetz, 7. Aufl 1997

Betriebsverfassungsgesetz, 4. Aufl 1996

Bd 3, 2. Aufl 2000

(zit: MünchArbR/Bearb)

zum BGB, 3. Aufl 1997

(zit: MünchKomm/Bearb)

Kommentar zum BGB, 13. Bearb $1993 \mathrm{ff}$ (zit: Staudinger/Bearb) 
